\title{
Public Policy and Disaster Justice
}

\author{
Stephen Dovers
}

\subsection{INTRODUCTION}

This chapter seeks to identify where, in the policy and institutional system that shapes emergency management and disaster policy, issues of 'justice' could be or are being addressed. It is more a commentary on the intersection of public policy (as it does or could exist) in the field of emergency management and disasters, and issues of justice as they are discussed in this book, than a substantive treatment, as the former is well-covered in referenced literature. As such, it is intended to define and open up a space for research and policy discussion around disaster justice as a public policy issue, rather than an attempt to fill that space.

Because disaster impacts and lack of opportunities for engagement in disaster mitigation can arouse considerable contestation and even anger, a starting assumption here is that emergency managers and others who shape and implement disaster policy do not intentionally create injustices. Rather, they may inadvertently or unknowingly create conditions whereby disaster impacts, or opportunities for empowerment, are not evenly or 'fairly' distributed, whether by way of their own actions or inattention,

\footnotetext{
S. Dovers $(\bowtie)$

Fenner School of Environment and Society, Australian National University, Canberra, ACT, Australia e-mail: stephen.dovers@anu.edu.au

(C) The Author(s) 2020 Justice, https://doi.org/10.1007/978-981-15-0466-2_3
} 
lack of resources, or by the constraints imposed by the parameters of existing policy and institutional arrangements or organisational capacity. I will extend that assumption to other policy sectors and individuals and organisations within them: that, for example, land use planners, health policy makers or infrastructure builders and custodians do not seek to create inequalities of disaster impact, preparedness or recovery, but rather such are undesirable by-products of decisions made for other reasons, including lack of linkages between emergency management and other policy sectors, oversight, issues of mandate and responsibility, or resourcing. It may be that policies and institutional settings could be changed to enhance justice outcomes-or some other goal-but such policy change is a matter for elected governments, advised by senior officials and groups from outside of government, but policy and management officials cannot generally step outside the limitations of existing policy even if they believe these to be deficient. In public policy debates, such a starting point allows a nonconfrontational approach to seeking redress of issues of procedural or distributional justice: constructive engagement begins with identification of an oversight and possible ways of doing things better, than it does with accusations of venality. Policy makers deserve some justice and understanding, too.

The chapter uses three sources. The first sources are the kind of justice issues identified elsewhere in this book, apparent from the disaster field. The second are frameworks and modes of analysis from the disaster policy literature (see further Cole, Dovers, Gough, \& Eburn, 2018; Dovers \& Handmer, 2014; Handmer \& Dovers, 2013; Lukasiewicz, Dovers, \& Eburn, 2017 and works referenced therein). The third is the existing institutional, policy and management system of Australian emergency management, a backdrop against which policy responses to injustice can be characterised. Apart from reference to some international situations discussed elsewhere in the book, the principles and general policy options exampled in the Australian context may be relevant elsewhere, subject to the usual caveats and cautions of comparative policy analysis and policy learning (Bennett \& Howlett, 1992; Rose, 2005), that is, to seek insights and understanding rather than models for adoption.

The next section considers the scope of 'disaster justice' as a policy arena, not just in the disaster policy and emergency management sector, which is an important consideration if policy options exist in other policy sectors, which this chapter argues they do. Following that, six sections 
briefly explore some core (and unremarkable) perspectives from the discipline and practice of public policy and the implications of considering these in terms of disaster justice. Along the way, general arguments are grounded or informed by situations and propositions described in other chapters of this book.

\subsection{Where Are the Boundaries of 'Disaster Justice Policy'?}

Four issues of scope are addressed here: the need to consider all aspects of emergency management; the definition of just processes and outcomes; the importance of policy integration across sectors; and the need to include all stakeholders in considering justice. The first issue of scope is that policy attention should span across the spectrum of Prevention-PreparednessResponse-Recovery (PPRR). There has been a slow, steady evolution of emergency management and disaster policy from focusing largely on Preparedness and Response to a greater emphasis on Prevention and (better) Recovery, articulated at the highest level in the Sendai Framework (UNISDR, 2015). This is congruent with an increasing linkage between disasters, sustainable development and human development, via the 2015 Agenda on Sustainable Development (UN, 2015) and the 2015 Paris Agreement on Climate Change (UNFCCC, 2015). These linkages and larger international agendas flow into many national and sub-national level policies, and are crucial to considerations of justice: climate change will exacerbate disasters, human development is damaged by disasters and disasters cause environmental harm. Opportunities for policy remedies to avoid differential vulnerability (minimising unjust distributional impacts), and different capacities to engage in disaster risk reduction activities (procedural matters) are arguably the greatest and more systemic in the stages of Prevention and Recovery. While the more immediate (and important) stages of Preparation and Response have justice implications, especially regarding distributional justice, Prevention (mitigation) reduces the chances of disaster impacts and thus unjust outcomes, and Recovery can likewise produce settlements and socio-economic conditions where the vulnerable are less at risk, with strong distributional but also procedural justice implications.

The second issue of scope is the question of what constitutes a 'just' process or outcome, or an injustice, in a specific situation, even where loss measurement, post-event inquiry, socio-economic impact assessment and 
similar processes may inform the identification of uneven impacts or opportunities. This may be contested and even irresolvable, as in many cases different but arguably valid conclusions as to specific instances of (in)justice will arise due to people's different perspectives, situations or value sets. If a group of people claim injustice, then that should be investigated: any eventual policy resolution aside, recognition of their concerns is a more just response than ignoring a voiced grievance. From a pragmatic public policy perspective, here we will take propositions of injustice or prospects of improved justice seriously, but temper these against extant literature and the reality of who does what, where and how in the policy and institutional landscape. In doing so, we will consider the implications of different concepts of justice (distributive, procedural, etc.) for public policy, predicting that these will expose quite different policy questions and options. In a later section, the ultimate political (rather than policy) judgement and resolution of different positions will be briefly discussed.

The third issue of scope is that, while the core focus is on emergency management and disaster policy, the creation of injustice or opportunities to improve justice in other policy sectors must also be considered (planning, health services, communications, housing, etc.). This recognises that it is in other policy sectors where vulnerabilities to hazards are often created, maintained or overlooked through inattention: disaster policy and emergency management seeks to manage or reduce, and eventually attends the consequences of, those vulnerabilities. Policy options to enhance just outcomes may be found more in policy sectors other than emergency management and disaster policy, but possibly harder to formulate and implement amidst other mandates and imperatives. In particular, the issue may be a lack of horizontal policy integration, whereby natural hazard and disaster considerations are not taken into account sufficiently in these other policy sectors. This may be via lack of mechanisms to allow or enforce such integration, or by lack of use of available mechanisms.

The final issue of scope is justice for whom? Issues of fairness and justice are mostly discussed with a primary focus on 'victims' of disasters, or those who may become so, through being vulnerable to the impacts of hazards. However, from a public policy perspective, a view that is both wider and of finer resolution is required. Justice for those impacted, or vulnerable to impacts, is indeed central, but injustices may be borne by responders, both paid and volunteer, emergency service organisation leaders and political figures, and firms. In this book, Ingham et al. (Chap. 12) identify the arguably unjust or at least untenable positions that community leaders 
may find themselves in a post-disaster event environment, subject to high expectations, with little support and scarce resources, on top of their own disrupted lives and normal demands on their time. Their study evidences the potential for a wider and finer resolution of the question 'justice for whom?' and generates both understanding of the situation and practical policy responses (in their case, back-filling leaders' positions and reconstituting Local Emergency Management Committee membership). Within sub-groups, access to justice, or the imposition of injustices, may vary: for example those who pay for flood insurance and thus increase their resilience, versus those who pay but later discover a clause differentiating types of flooding that restricts their claim for damages, versus those who cannot afford insurance and call on the public purse post-event, versus those who are capable of affording insurance but do not on the expectation that the state will assist them nonetheless. Are those in the final category being unjust against the other two, and on the wider public?

Returning to justice afforded to emergency managers themselves, in Australia the prime lesson-drawing and blame-attributing mechanismpost-event inquiries - focus heavily on emergency management agencies and their professional officers, and very little on firms, volunteers, households or individuals (Cole et al., 2018). With 'shared responsibility' and similar policy principles stated internationally and nationally, requiring contributions across the PPRR spectrum from public, private and community sector actors, this is a strange lack of attention. As discussed by Eburn in this book (Chap. 7), many post-event inquiries are adversarial and blame-seeking rather than restorative, and may be seen as not delivering justice to professional emergency managers and responders.

Issues of scope summarised, the following sections explore some implications for disaster justice issues of six basic (and often interrelated) lenses of public policy: (1) whether justice-relevant decisions are a matter for public policy or more value-laden politics; $(2)$ if the former, where in policy process they can be attended to; (3) which sector, agency or individual has the major or ultimate responsibility or power over the matter at hand; (4) in addition to the legal or political mandate, what actors outside of government contribute to justice or injustices; (5) whether it is a matter of disaster policy or emergency management practice, or a matter for another policy sector; and (6) whether enhancement of existing powers or policies can provide remedy, or whether the issue requires the creation of new mechanisms. 


\subsection{Policy OR Politics?}

While some may view policy as a rational, neutral practice, or believe that it should be, the mechanisms of public policy implement social and political goals that have been argued and negotiated more broadly across society. 'Political decisions' are often viewed poorly, but in the best sense are where sufficiently supported social goals, or indeed unpopular but necessary decisions, are defined by elected governments and then passed through the public policy system of a jurisdiction for implementation (element 1, Table 3.1). Davis et al. (1993, p. 257) put it well (original emphasis):

Politics is the essential ingredient for producing workable policies, which are more publicly accountable and politically justifiable ... While some are uncomfortable with the notion that politics can enhance rational decisionmaking, preferring to see politics as expediency, it is integral to the process of securing defensible outcomes. We are unable to combine values, interests and resources in ways which are not political.

Policy is imbued with values, including different interpretations of the public interest, as manifestations of political decisions. A justice issue (or occurrence of injustice) might be a matter for public policy and public administration, and can be attended to by public officials with nongovernment partners within existing policy settings, or might rather be a value question requiring a political judgement and decision to rectify. Often, attention to injustices require a political decision to change policy goals or resourcing levels for 'policy' to then proceed to address the situation. Consider the alternate scenario presented by Alexandra in this book (Chap. 4), of a very different manner of land use planning in fireprone peri-urban and rural areas. Land use planning is, constitutionally, a matter for states and territories, and while all planning regimes consider natural hazards, giving prime consideration to that above all over policy goals has never occurred. While existing settlements and dwellings could not conceivably be altered in the near term or substantially, unless as dwellings age they are prohibited from being rebuilt, it is entirely possible that a jurisdiction faced with increasing exposure to bushfire (aka wildfire) could decide to manage future risk by only permitting new 
Table 3.1 Framework for policy and institutional analysis for emergencies and disasters

1. Problem framing

2. Policy framing and strategic policy choice

4. Policy monitoring and learning

Cross-cutting policy principles

Institutional design imperatives
1. Social debate of problems.

2. Monitoring, research.

3. Identification of direct and indirect causes, including vulnerability and resilience.

4. Assessment of other policies.

5. Assessment of risk and uncertainty.

6. Definition of policy and institutional problems.

7. Choice of general policy style/styles.

8. Identification of policy principles.

9. Definition of policy goals.

10. Policy statement.

11. Policy instrument choice.

12. Implementation planning.

13. Provision of resources (multiple forms).

14. Communication and information strategies.

15. Enforcement and compliance provisions.

16. Establishment of monitoring mechanisms.

17. Monitoring and routine data capture.

18. Learning from events.

19. Evaluation.

20. Adaptation, cessation, problem redefined.

Whole-of-government coordination.

Transparency and accountability.

Public participation.

Coordination of actors and organizations.

Use of legal systems and instruments.

Clarity of responsibilities.

Purposefulness and persistence over time.

Information richness and sensitivity.

Flexibility and adaptability.

Source: Adapted from Handmer and Dovers (2013, p. 64)

This is not a model, but a heuristic checklist of elements that often apply and may be crucial in a given situation. In both policy analysis and reality, the implicit linearity below will generally not hold: focus may be on a small number of elements; an exercise or attention may commence at a number of points; reiteration or feedback loops will often occur, causing reconsideration of an earlier element 
settlement in defined areas in the manner Alexandra describes. That could be expressed in a new land use and dwelling approval regime enabled by state legislation, which would then be implemented by the appropriate state and local government agencies. However, such a policy shift would be considered by some as a radical shift in the face of actual and assumed rights, historical patterns of land use, and social expectations, and would require a 'brave' political decision from a state government, with certain strong opposition in public debate. Many would see such constraint on peoples' choice of where and how to live as deeply unjust, even if it saved some from exposure to risk of property loss and death. If land already zoned to allow future development was affected, legal recourse would likely be pursued. Public policy and public administration could implement such a regime, but initiating it would be a deeply political matter.

Consider another example of the justice dimension of political decisions. The patchy adoption of flood insurance (not insuring, as well as inadequate policies) and thus the uneven ability to recover losses, repeatedly arises as an issue following significant floods in Australia and elsewhere. It would be entirely possible for a government to define a policy whereby those who are uninsured in instances of known risk would not be eligible for recovery aid (perhaps with a pro-justice subsidy or exemption for poorer households). That would incentivise selfreliance and use an available, well-known fiscal policy instrument (insurance). Now consider a political leader confronting affected households and whole communities saying "bad luck, you were told to insure and you didn't", and being repaid with community anger and electoral loss. However economically logical and effective the policy, in the face of human suffering, a back down from that policy position might not be only 'political' in the negative sense, but 'political' also as an expression of human sympathy and sense of justice for fellow community members.

\subsection{What Part of the Policy Process?}

Behind the call or need for a 'policy response' there lies significant and important detail, as the public policy process is complex, comprising many parts and the required response may be available or not in various parts. So, at which 'stage' of the policy process, or via which element or 
combination of elements of a policy process is a particular justice issue (1) caused by, or (2) can be attended by: policy formulation, policy design, policy implementation, policy monitoring and evaluation? Those four 'stages' are typical of simple policy models, but Table 3.1 (from Handmer \& Dovers, 2013) provides greater detail of specific and general elements of the disaster and emergency policy process. Usually a justice issue, or a suite of issues, will need to be attended to in multiple parts of the policy process, or it may already be catered for but could be more effectively implemented. An issue may require broad social and political debate (element 1 , important regarding public participation and thus procedural justice) and/or further investigation (elements 2-5), before a problem suitable for policy attention and action (element 6 ) can be defined. Whether those preliminary elements are required or not (the situation and problem may be evident already), policy formulation (elements 7-10) is a substantial task, well before the detail of policy design and implementation (elements 11-16). Monitoring of the success or failure-it is usually somewhere between-of a policy programme should be an ongoing effort, with clear goals and metrics defined and appropriate data capture that allows rigorous evaluation. Within those broad categories of elements of the policy process, some will demand detailed analytical and design effort, such as choosing the policy instrument/s to be deployed (a tax incentive, a stricter regulation, public education campaigns, etc.) or the statutory settings to enable implementation (see shortly below in the case of bushfire). Policy instrument choice involves the application of a range of selection criteria, including justice-relevant ones such as distributional impacts and communicability (Table 3.1).

Importantly, public policy is almost always an iterative (indeed messy) rather than linear process, with attention starting at different 'stages' or with different elements, and in line with different stakeholders' values and motivations, and moving back and forth between problem identification, policy design, implementation and policy monitoring as experience and understanding evolve such as when new information becomes available.

The study by March et al. in this book (Chap. 5) can illustrate the complexities and multiple choices outlined above. The Wye RiverSeparation Creek bushfires exposed causes and effects that share similar characteristics to other fires: a risky environment where existing settlement 
patterns, dwelling construction and household behaviours led to significant loss when combined with severe fire weather. Should society wish to prevent future harm, what are the policy questions? One is whether the lessons should inform future planning and development control via a strong, statutory and regulatory regime that tightly controls future development in a shift from historical and current patterns (similar to the Alexandra scenario discussion above): a deeply political policy direction that might well be contested by some stakeholders (Table 3.1 element 1, with subsequent action through the parliamentary and policy processes). Less controversial would be a focus on more targeted communication to encourage actions to increase the fire resistance of dwellings, or funding programmes to enable better Prevention and Preparation, or a fiscal incentive such as property rate rebates to achieve the same. These options are the detail beneath element 11 in Table 3.1-policy instrument choice-where the means to the ends of policy are chosen, detail exposed further in Table 3.2. We know the social/policy outcome that is desired (better management of households and surrounds to minimise/reduce fire hazard) and have to select the policy tool to achieve that. Instrument choice is fundamental to public policy, and has justice implications that we now explore briefly.

Table 3.2 provides a menu of policy instruments-the tools available to governments and their partners to achieve agreed social and policy goals - and Table 3.3 presents a set of criteria against which instruments can be compared (from Handmer \& Dovers, 2013, tailored to the disaster field but not dissimilar to many other iterations in the public policy literature). There are many instrument options, and many criteria, and choice is not a deterministic, easy matter but the two lists can guide discussion and choice.

The strong, planning regime option identified above in a case such as Wye River (Chap. 5) would call upon a legislated and enforced land use planning regime (options 6 and 7 in Table 3.2). The less confronting but complementary options to encourage self-defence involve options 3-4 and 8-10 (typically, a policy response will involve use of more than one policy instrument). The considerations regularly taken into account by policy makers (the criteria in Table 3.3), whether satisfactory or not, already include justice-relevant factors, even if not explicitly stated. 


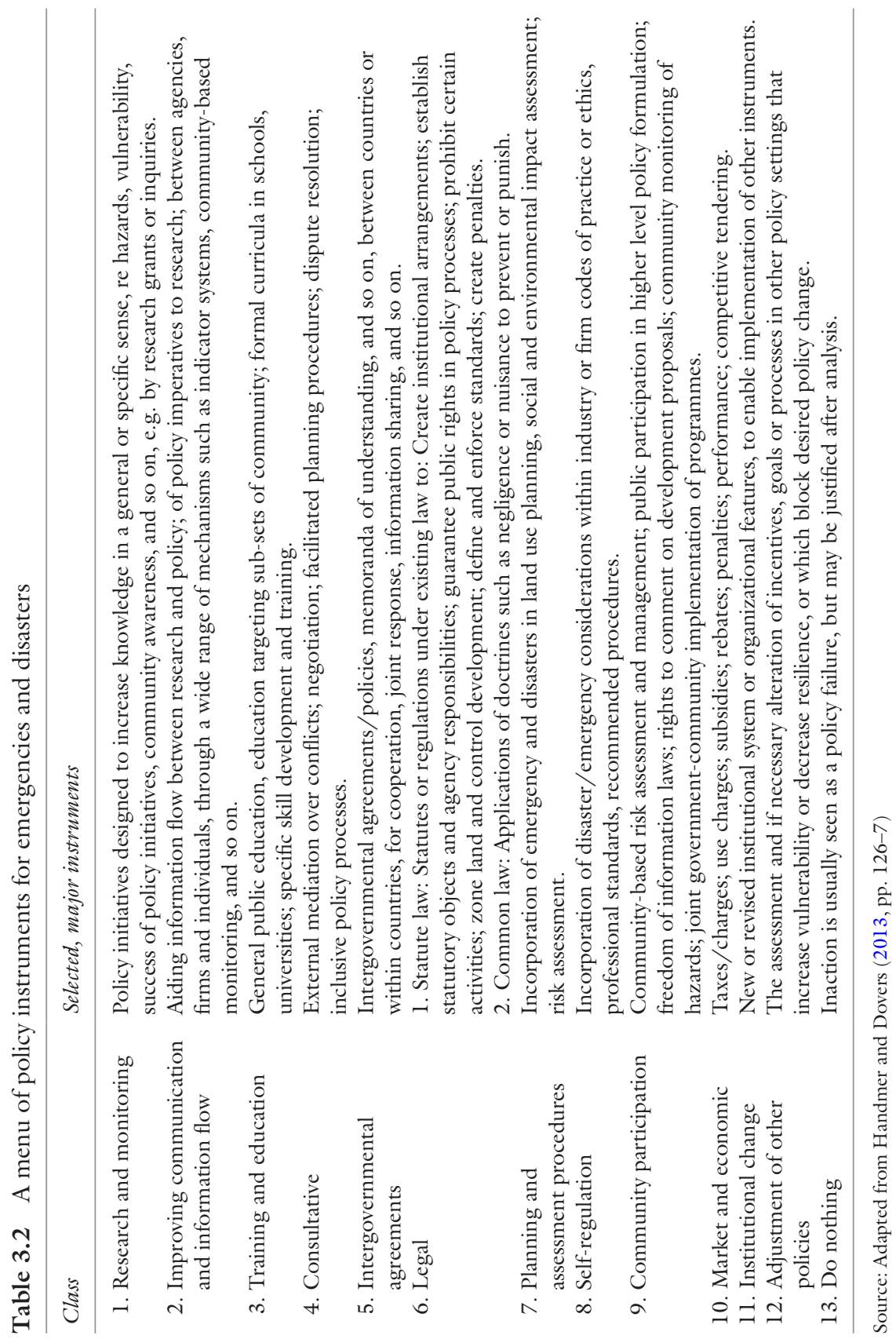


Table 3.3 Criteria for selecting policy instruments

\begin{tabular}{|c|c|}
\hline Criteria & Question, relative to other instruments \\
\hline 1. Dependability & $\begin{array}{l}\text { How certain is it that the instrument will achieve policy } \\
\text { goals? }\end{array}$ \\
\hline 2. Timeliness & Can the instrument be developed and applied in time? \\
\hline 3. Cost and efficiency & $\begin{array}{l}\text { What is the cost and efficiency of the instrument, relative } \\
\text { to achieving goals? }\end{array}$ \\
\hline 4. Systemic potential & $\begin{array}{l}\text { Does the instrument address underlying causes, or only } \\
\text { address symptoms? }\end{array}$ \\
\hline $\begin{array}{l}\text { 5. Information and } \\
\text { monitoring requirements }\end{array}$ & $\begin{array}{l}\text { Is needed information available to design and implement } \\
\text { the instrument? }\end{array}$ \\
\hline 6. Distributional impacts & $\begin{array}{l}\text { Will implementation of the instrument have inequitable } \\
\text { impacts across the affected population; can these be } \\
\text { managed? }\end{array}$ \\
\hline $\begin{array}{l}\text { 7. Political and institutional } \\
\text { feasibility }\end{array}$ & $\begin{array}{l}\text { Is use of the instrument feasible in terms of political } \\
\text { support and institutional capacity? }\end{array}$ \\
\hline $\begin{array}{l}\text { 8. Ability to be enforced or } \\
\text { avoided }\end{array}$ & $\begin{array}{l}\text { Can implementation/uptake of the instrument be } \\
\text { ensured or enforced? }\end{array}$ \\
\hline 9. Communicability & $\begin{array}{l}\text { Can the desirability of using the instrument be } \\
\text { communicated to those implementing it or impacted by it? }\end{array}$ \\
\hline 10. Flexibility & $\begin{array}{l}\text { Is the instrument capable of being adapted as knowledge } \\
\text { or circumstances change? }\end{array}$ \\
\hline
\end{tabular}

Source: Adapted from Handmer and Dovers (2013, p. 129)

Consider the following policy instrument choice criteria and the case of bushfire, where one criterion may not rule out an option but will focus attention on a justice issue and how that can be attended:

- Criterion 6 (distributional impacts): A policy instrument may be deemed effective and efficient, but impose financial or other burdens unfairly on a segment of the community, such as the cost of required fire-safety retrofitting for poorer households (distributional justice). That may be a reason to not select an instrument, or to lessen the distributional impact through associated grants or transfer payments.

- Criteria 5 (information) and 9 (communicability): Access to information and therefore the ability to comply with or gain benefit from measures such as building code changes, flood risk overlays, financial payment programmes or similar may be uneven across a community (procedural and informational justice). This instructs careful design to ensure policy changes and opportunities are made known and accessible to specific groups in the community (e.g. Chap. 17). 
- Criterion 8 (compliance): Although frequently considered regarding the public finance implications, compliance also applies to households and firms, particularly with regulatory instruments, where the costs of compliance and reporting (a subset of distributional impacts) may be either undesirably high overall or for a particular segment of the community. An example would be monitoring fire preparedness measures at the household level to qualify for rate or insurance rebate incentives. Again, this may rule out an instrument, or suggest measures to alleviate these burdens.

- Finally, criterion 3 (cost and efficiency). These have justice implications in so far as gross cost and relative efficiency determines the quantum of resources required. It may well be possible to significantly reduce one category of risk (say, from bushfire) but only at the expense of other risks (say, flood) from a given budget, or only in some places and not others, with implications for distributional justice. Such difficult choices of priority and spending are universal in public policy, and every choice to address one problem, for some people, limits the ability to do something else for others. All policy choices involve trade-offs and potential creation of actual or perceived injustice.

A stronger justice orientation in disaster and emergency management could be achieved by stating criteria such as those above more clearly in overarching policy and decision making procedures, and emphasising their importance. That would empower decision makers implementing policy to act with a clear mandate and greater confidence in seeking justice outcomes.

Utilising standard frameworks from public policy such as Tables 3.1, 3.2 , and 3.3 does not make formulating policy responses easier, but encourages more explicit consideration of multiple factors, including those with justice implications.

\subsection{Whose Responsibility?}

In deploying instruments to achieve a social and policy goal, a key question is what individual or organisation has the mandate and capacity to initiate, develop and implement the policy. Two considerations here, within government and outside of government: (1) who has that legal and political authority, generally being a government or part thereof, or dele- 
gated by that 'responsible authority' to someone else; or (2) someone outside of government but necessarily involved in the formulation, implementation and/or monitoring of a policy initiative.

Regarding (1), with respect to a justice-related decision (the policy goal with distributional impacts or a procedural decision on who is allowed to have input into a decision), at which level of government, (national, state/ provincial, local) or within the power of which government agency at a particular level of government does primary responsibility lie? Mistaking who is responsible will dilute otherwise valid arguments for redress of injustice. While policy involves partners outside of government, the state has a foundational role and is generally the primary agent in provision of resources and underpinnings of statutory, financial, informational and administrative competence. Clarity over who could or should have responsibility is important and needs to consider jurisdiction, portfolio, source of authority and legal mandate. Certain responsibilities and roles can be defined by legislation and government agency mandates, including who may participate in policy processes, such as through submissions or identified avenues for engagement. These can be clear, and also can be politically and legally challenged in cases where justice issues such as protection of vulnerable groups or inclusion of diverse voices are perceived not to have been fulfilled.

In regards to (2), the PPRR spectrum and the modern policy principle of shared responsibility (or, collaborative approaches) requires actions by non-government actors, including households, community groups, NGOs and private firms. Calgaro et al. (Chap. 17) show the potential power of collaborative engagement between government and NGOs to implement and achieve policy goals that are directly relevant to justice considerations, enhancing the safety of the disabled in disaster risk reduction. For a policy maker, however, the allocation of roles to non-government actors is at once highly desirable for both practical and ideological reasons, and yet problematic for reliable acquittal of 'responsibilities'.

While the primary expectation for most aspects of PPRR has been placed on governments (e.g. Victorian Government, 2010), the policy goal of 'shared responsibility' instructs that seeking to locate problems or opportunities regarding disaster justice must consider non-government actors (households, firms, community groups, industry associations, professions, NGOs) as well (Lukasiewicz et al., 2017). While broader consideration of policy partnerships and poly-centric or network governance are relevant, the focus here is the justice implications that individuals and 
organisations undertake a PPPR function even though not required legally or politically nor funded to do so. There are three justice-related aspects to this: (1) seeking to impose a responsibility on an entity that may not have the resources to fulfil that expectation might be unfair (unjust); (2) from a pragmatic public policy perspective, to rely on an unenforceable expectation involves some risk of policy failure and thus unintended outcomes, including justice impacts; and (3) voluntary engagement in a policy process raises issues of representation and the validity of inputs to policy.

Some roles in disaster response by non-government actors are wellestablished and predictable, and often the subject of clear agreements with governments (for example the prominent role of Red Cross and Red Crescent). Other roles may be less prominent or sustained but highly effective, targeting a specific need: Calgaro et al. (Chap. 17) describe a positive case. Other roles and contributions are locally regular, critical but tenuous (e.g. Ingham et al., Chap. 12). Others again are dynamic, unpredictable and present a tension of both problem and opportunity for disaster management. A high profile example is 'spontaneous volunteers' post-disaster (on this and related volunteer issues, see McLennan, Whittaker, \& Handmer, 2016)—such waves of help are unpredictable, can be crucial, but can create risks to both those affected and responders if undertaken without due care, and questioning or controlling the right of people to assist their own community has justice implications. More broadly, there is the procedural justice question of a community's right to identify risks and assets and fashion their own strategies versus more topdown, professionally driven and agency-driven approaches: the values and thus priorities (and losses) from a community perspective may be overlooked by outsiders, as discussed by Schlosberg et al. (Chap. 13).

The most unpredictable but crucial non-government actors are individuals and households, who are central to the 'shared responsibility' model, but who are diverse in their adoption of risk reduction actions and in many cases free from specific obligations. The household that loses their well-prepared property due to ignition spread from unprepared, fuel-rich neighbouring houses may feel a sense of injustice. If coercive policy measures were in place to force pre-fire season preparation, some households would doubtless view this imposition as unjust. This is a space replete with highly varied personal, political and theoretical positions on the role of individuals, communities and the state that are central but beyond scope here (Lukasiewicz et al., 2017; McLennan \& Eburn, 2015). The fact that post-event inquiries, at least in Australia, are largely 
silent on the role of individuals, households and even volunteers (Cole et al., 2018) means an important potential impetus for policy debate on these actors is lacking.

\subsection{Disaster Policy, or Something Else?}

Importantly, issues of justice may not be caused within or be addressable by 'disaster policy', but in fact more likely can only be rectified in other policy domains such as land use planning, communications, infrastructure or health services. Bluntly, emergency management and disaster policy is as much about reactively addressing the impacts of vulnerabilities created or ignored by other policy sectors, as it is about proactively reducing vulnerability or enhancing resilience. This invites consideration of policy integration (aka mainstreaming) where disaster-relevant measures are implemented within those other sectors and portfolios. This is a large topic and a constant but often unachieved aim of disaster and emergency professionals and agencies whose primary mandate is Preparedness and Response, but that is beyond scope here. However, some indications of the justice-relevant aspects of this emerge in this book and can serve as indications.

The role of land use planning (Chaps. 4 and 5; March \& Dovers, 2017) is one of the more prominent, where vulnerability is created, or at least claimed to be so, by planning decisions or oversights that place households in disaster-prone areas. While significant measures are included in many planning schemes, such as identified flood or fire risk zones and standards for buildings, there are tensions between risk reduction and the many other imperatives that drive planning. Housing affordability and consumer preference for bushland proximity, as well as sheer economic development pressure, raise questions of justice, or perceived injustice, if housing and development choices are constrained or made more expensive by imposed risk reduction measures. Chapter 11 delves behind the usually simplistically treated issue of arson to expose evidently unjust precursors to many offenders' ignitions. As with many policy problems, policy can and should attend the symptom (policing, education, punishment) but could also consider the causes related to alienation and disaffection that lie well outside fire management and policing (criterion 4, Table 3.3). This would require a decision by society and government to widen policy scope. 


\subsection{New Mechanisms, or the Same but Better?}

A central question from a public policy perspective is whether addressing issues of justice (assuming this is found to be needed) requires (1) wholly or substantially new policy framing, policy instruments or institutional settings; or (2) revisions to the implementation of existing policy mechanisms (i.e. more or differently applied of the same). The likelihood of both success and the speed of reform is almost always greater in the case of the latter-management actions are changed more quickly than policy details, which are more easily and quickly changed than entire policies, and creation of a new institutional setting is an even longer-term prospect. An example from this book, addressing procedural justice, is Ingham et al.'s (Chap. 12) recommendation for adjusting membership of local emergency management committees, easily done, likely effective, and through an existing structure.

That example raises the question of how quickly a policy change can be implemented to address a justice or other issues (see further Handmer \& Dovers, 2013, pp. 158-9). Institutional settings and major legislative instruments take significantly longer to change, for good reason, than organisational detail or subsidiary regulations. Whole policy programmes are not renewed quickly, but implementation procedures or guidelines under them may allow more rapid adjustments. If a positive outcome can be achieved by adjustment within broader policy and institutional settings, then a more rapid redress of justice concerns may be possible (or, longer term, substantial institutional change may indeed be required).

\subsection{Discussion and (In)Conclusions}

The above discussion of six policy issues and their disaster justice implications opens a space about how to address (in)justice within the pragmatic and complex disaster policy environment. It also shows how many long-standing disaster policy and emergency management matters have clear, and sometimes less clear, justice implications. That should not surprise, as disasters lead to death, destruction and loss unevenly, so of course injustices occur. Two questions arise: does or can consideration of the disaster-justice nexus contribute to (1) justice research, and (2) disaster policy? 
On (1), the high stakes, context-dependency, uncertainty and dynamic nature of disasters does make for a fertile field of inquiry to explore issues of justice. Other contributions in this book demonstrate this in many detailed instances. On (2), issues of unequal access to decision making, vulnerability and impacts are standard topics in disaster policy and emergency management, but a justice research lens can enhance thinking in two ways. One is that the very concepts of justice and injustice sharpen the importance of inequalities: as Calgaro et al. (Chap. 17) identify, these become matters of human rights. The second is that the language of justice research-distributional, procedural, informational, relational, and so on-provides a more comprehensive set of descriptors and thus deeper perspective than usual in the disaster field, compared to simply 'equality', and this can increase the resolution of understanding (and, therefore, potentially the effectiveness and targeting of policy responses).

In Chap. 8, Schilizzi and Azeem in their analysis of post-flood housing in Pakistan demonstrate the potential for justice principles, via different and valid approaches to equality, to aid policy analysis. While their analysis does not provide a singular policy answer, it does lead to a more explicit understanding of the logic and implications of different approaches to a particular disaster policy question. That kind of approach has significant potential.

To conclude this chapter, Table 3.4 presents a tentative matrix filled with selected, illustrative examples that ask if issues of justice emerge as a result of risk borne unevenly or unfairly, then (1) what are the risks, (2) who bears that risk, (3) at what 'stage' on the PPRR spectrum, (4) what is the justice issue, and (5) what are the public policy options applicable to redressing the issue?

Table 3.4 invites further detail and discussion, but indicates a way to structure a discussion between justice research and disaster policy in a potentially constructive way among the respective concerns and core concepts of disaster policy makers, emergency managers, justice researchers and practitioners, as well as of those vulnerable to and impacted by disasters. Disasters, policy and justice have commonalities: all three are complex, unpredictable and contested. This chapter and this book suggest that a conversation between the two fields of research and practice can be better structured and fruitful. 


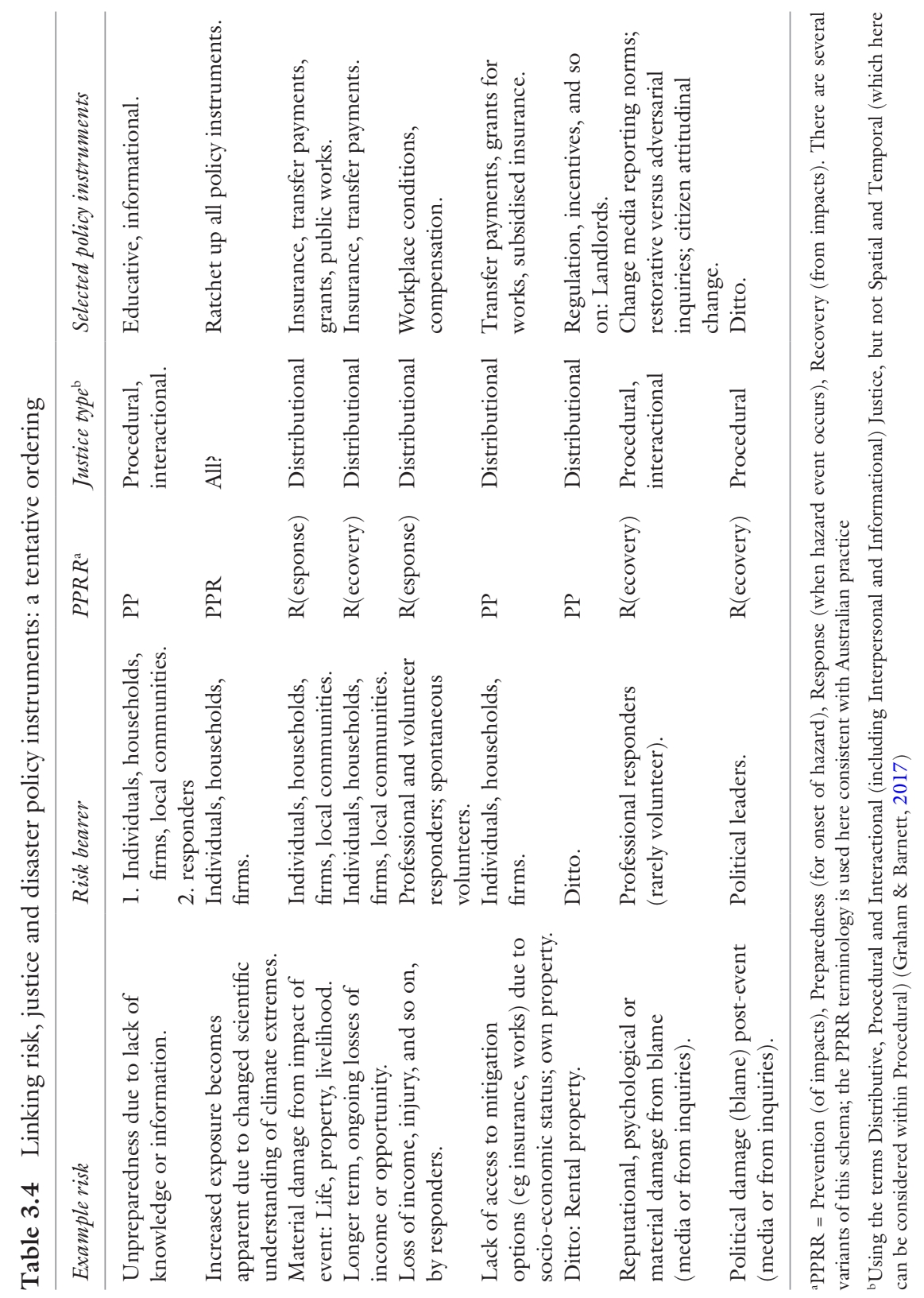




\section{REFERENCES}

Bennett, C. J., \& Howlett, M. (1992). The Lessons of Learning: Reconciling Theories of Policy Learning and Policy Change. Policy Sciences, 25, 275-294.

Cole, L., Dovers, S., Gough, M., \& Eburn, M. (2018). Can Major Post-Event Inquiries and Reviews Contribute to Lessons Management? Australian Journal of Emergency Management, 33(2), 34-39.

Davis, G., Wanna, J., Warhurst, J., \& Weller, P. (1993). Public Policy in Australia. Sydney: Allen \& Unwin.

Dovers, S., \& Handmer, J. (2014). Disaster Policy and Climate Change: How Much More of the Same? In A. Ismail-Zadeh, J. Urrutia-Fucugaughi, A. Kijko, K. Takeuchi, \& I. Zaliapin (Eds.), Extreme Natural Hazards, Disaster Risks and Societal Implications (pp. 348-358). Cambridge: Cambridge University Press.

Graham, S., \& Barnett, J. (2017). Accounting for Justice in Local Government Responses to Sea-Level Rise. In A. Lukasiewicz et al. (Eds.), Natural Resources and Environmental Justice: Australian Perspectives (pp. 91-103). Melbourne: CSIRO.

Handmer, J., \& Dovers, S. (2013). Handbook of Disaster Policies and Institutions: Improving Emergency Management and Climate Adaptation (2nd ed.). London: Routledge.

Lukasiewicz, A., Dovers, S., \& Eburn, M. (2017). Shared Responsibility: The Who, What and How. Environmental Hazards, 16, 291-313.

March, A., \& Dovers, S. (2017). Mainstreaming Urban Planning for Disaster Risk Reduction. In K. Vella \& N. Sipe (Eds.), Australian Handbook of Urban and Regional Planning (pp. 231-246). Taylor \& Francis.

McLennan, B., \& Eburn, M. (2015). Exposing Hidden-Value Trade-Offs: Sharing Wildfire Management Responsibility Between Government and Citizens. International Journal of Wildland Fire, 24, 162-169.

McLennan, B., Whittaker, J., \& Handmer, J. (2016). The Changing Landscape of Disaster Volunteering: Opportunities, Responses and Gaps in Australia. Natural Hazards, 84, 2031-2048.

Rose, R. (2005). Learning from Comparative Public Policy: A Practical Guide. London: Routledge.

(UN) United Nations. (2015). Transforming Our World: The 2030 Agenda for Sustainable Development. A/RES/70/1. New York: United Nations.

(UNFCCC) United Nations Framework Convention on Climate Change. (2015). Report of the Conference of the Parties on Its Twenty-First Session, Held in Paris from 30 November to 13 December 2015. Addendum. Part Two: Action Taken by the Conference of the Parties at Its Twenty-First Session. In Conference of the Parties 21. Paris, France: United Nations. 
(UNISDR) United Nations Office of Disaster Risk Reduction. (2015). Sendai Framework for Disaster Risk Reduction 2015-2030. In Third UN World Conference. Sendai, Japan: United Nations.

Victorian Government. (2010). 2009 Victorian Bushfires Royal Commission. Final Report. Retrieved from www.royalcommission.vic.gov.au/CommissionReports/Final-Report.html 